\title{
Exploring the barriers to implementing National Health Insurance in South Africa: The people's perspective
}

\author{
R V Passchier, MB BCh, MSc \\ Department of Psychiatry and Mental Health, Faculty of Health Sciences, University of Cape Town, South Africa; Department of Psychiatry, \\ Steve Biko Academic Hospital, Pretoria, South Africa; and Bheki Mlangeni District Hospital, Soweto, South Africa
}

Corresponding author: $R$ V Passchier (ruthpasschier@gmail.com)

This article explores the challenges of implementing the proposed National Health Insurance for South Africa (SA), based on the six building blocks of the World Health Organization Health System Framework. In the context of the current SA health system, leadership, finance, workforce, technologies, information and service delivery are explored from the perspective of the people at ground level. Through considerations such as these, the universal health coverage goals of health equity, efficiency, responsiveness and financial risk protection, might be realised.

S Afr Med J 2017;107(10):836-838. DOI:10.7196/SAMJ.2017.v107i10.12726

On 10 December 2015, the South African (SA) Department of Health proudly presented the nation with the White Paper for a National Health Insurance (NHI). The key features of $\mathrm{NHI}{ }^{[1]}$ which are expected to be fully implemented by 2030, are:

- universal access

- mandatory prepayment of healthcare

- comprehensive service

- financial risk protection

- single fund

- strategic purchaser

- single payer.

However, a prerequisite for successful universal coverage, as defined by the World Health Organization (WHO), is a strong, efficient, wellrun health system that meets priority health needs through peoplecentred, integrated care. ${ }^{[2]}$ With this in mind, challenges within the six building blocks of the WHO Health System Framework ${ }^{[3]}$ (Fig. 1) will be explored in the SA context, from the perspective of the people who will become a part of the new health system.

\section{Finance}

The NHI will introduce a mandatory prepayment of healthcare costs, which is distinct from other modes of payment such as voluntary prepayment, out-of-pocket payments and tax. ${ }^{[1]}$ Currently, primary

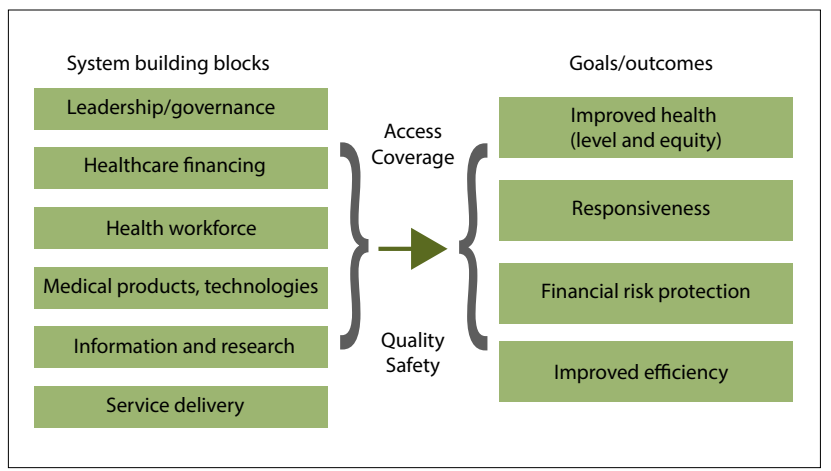

Fig. 1. The World Health Organization Health Systems Framework. ${ }^{[3]}$ healthcare is free in SA, and hospital-care costs are waived for vulnerable populations and those in the lowest income bracket. For the remainder of patients, hospital fees are relatively low (having not kept pace with inflation) and not strictly enforced, and no rigorous means test is in place to decipher income bracket. ${ }^{[4]}$ Therefore, the majority of South Africans pay little or nothing for public healthcare, and so do not risk incurring catastrophic health costs. As seen in Kenya ${ }^{[5]}$ low fees for hospital service reduce the incentive for potential contributors to enrol in an NHI system. ${ }^{[4]}$ How can we justify to the people that they should pay for a service that they used to get free? This is similar to the argument used by trade unions opposing the NHI in 1997. ${ }^{[4]}$

The quality of the current SA public health sector is poor, performing worse than the average for an upper-middle-income country. ${ }^{[6]}$ Low perceived quality of care can result in continuing out-of-pocket payments and expensive private health insurance, ${ }^{[4]}$ as demonstrated in Thailand. ${ }^{[7]}$ Lack of perceived benefit can also affect participation. This was the case in Kazakhstan, where very few self-employed individuals registered with the NHI, despite its being legally required ${ }^{[8]}$ For an NHI to be feasible and acceptable to the payers, it must offer significant advantages over existing services. ${ }^{[4]}$ Systemic problems within the current system could adversely affect the ability of the NHI to translate additional finances into better quality healthcare, and the government risks introducing further inefficiencies into an already-struggling system. ${ }^{[6]}$ Not only would this arouse animosity among those paying for but not benefiting from the NHI, but it would also impose a financial burden on all households, with or without private health insurance, with no significant improvement in the quality of care received. ${ }^{[6]}$

\section{Goverinance}

Alex van den Heever ${ }^{[9]}$ of the University of the Witwatersrand suggests that financing the NHI is the least of the health system's problems; rather, the main problem is with how the money is to be spent. 'Lack of governance and accountability, and corruption, has led to several provinces going into chronic budget deficit. ${ }^{[9]} \mathrm{A}$ fundamental criticism of the NHI is that its implementation will be constrained by the poor administrative and managerial capacity of the state. ${ }^{[10]}$ The system is 
threatened by poor co-ordination between national, provincial and district levels. ${ }^{[1]}$ The NHI system will need to provide clarity regarding roles, and mechanisms of communication, to ensure the effectiveness of management on the macro, meso and micro levels.

Nigeria's experience shows that interest and strong political leadership when implementing an NHI enhances the pace of the policy process. ${ }^{[12]}$ However, when new systems are implemented, local politicians who could help to identify obstacles are often excluded. ${ }^{[13]}$ Although political will is essential, it is necessary to involve all stakeholders when attempting any reform. ${ }^{[1]}$ Vision, collaboration and oversight of the NHI will require co-operation and input from multiple levels, getting community members, service users, health workers and politicians together from the start, to share their views about the system and to commit to working together to solve problems. ${ }^{[13]}$ As Bishai et al ${ }^{[13]}$ explain, 'People who own the problem can anticipate the most likely social obstacles to its resolution, and their participation is essential.' Without the vision and oversight of all those using and working in the health system, the NHI may face resistance from personnel at ground level.

\section{Health workforce}

The Minister of Health, Dr Motsoaledi, has said that the country needs to triple its number of doctors for the NHI to work. ${ }^{[9]}$ Currently, $70 \%$ of medical practitioners work in the private sector. This is not surprising, since a doctor in public practice, working in an under-resourced environment, will see up to 17 times the patient load of a private practitioner ${ }^{[6]}$ The country is currently funding new medical schools to increase the number of doctors produced yearly. ${ }^{[9]}$ However, instead of focusing on training new professionals (who will almost certainly end up supplying the private sector), the problem that should be addressed is: why are the staff leaving?

Low levels of staff motivation, owing to a discouraging work environment, with poor equipment, short supplies, high vacancy rates and mounting workloads, are the norm in public health facilities. ${ }^{[6]}$ These 'push factors' need to be addressed in order to retain the number of health workers required for the new system to function. The public sector will need to utilise, support and motivate the available health workers by effective human-resource management and quality management tools, to create working environments that improve morale and job satisfaction, and enable staff to achieve their personal and professional goals. ${ }^{[6]}$

\section{Service delivery}

A history of colonialism, apartheid and separate development has impacted heavily on the misdistribution of and differential access to health services in SA. ${ }^{[14]}$ The country was founded on principles of inequity, and to this day suffers the consequences, being regarded by analysts as having one of the most iniquitous health systems in the world. ${ }^{[9]}$

The NHI claims to prioritise services to those populations most in need. ${ }^{[1]}$ However, capacity varies between provinces, making their ability to implement service uneven. ${ }^{[15]}$ This poses the risk of widening the equity gap, unless targeting and incentives can support the poorest-served provinces. ${ }^{[15]}$ It is unclear how the NHI will redistribute the human resources and infrastructure that have been firmly set in centuries of unequal distribution along public-private, rural-urban, primary-tertiary and poor-rich lines. ${ }^{[6]}$

\section{Information and research}

The NHI will bring with it the proposed National Health Information Repository and Data system. This aims to improve monitoring and to track health status, quality assurance and healthcare utilisation. ${ }^{[1]}$
However, there is a lack of monitoring and evaluation mechanisms at all levels of the health system, and inadequate human resources to provide such services. ${ }^{[11]}$ Furthermore, past studies have shown SA to be 'data rich but information poor, ${ }^{[15]}$ since data systems do not always provide nationally representative, good-quality information in a timely manner. ${ }^{[15]}$ Capacity building to improve data collection, and making use of new digital technology, must be considered to improve implementation. Streamlining of translation into policy, programmes and practice should be prioritised to avoid the waste of this valuable resource.

\section{Medical products and technologies}

The private sector has a major role to play in developing innovative uses of medical products and technology, such as new diagnostics. ${ }^{[16]}$ The NHI plans to purchase services from accredited and contracted private specialists and private hospitals. ${ }^{[1]}$ The unsuccessful privatepublic partnership (PPP) in the neighbouring country Lesotho, along with international evidence, shows that PPPs can be risky and costly, and can fail to advance universal and equitable health coverage. ${ }^{[17]}$ Furthermore, the high cost of private-provider fees is currently a barrier to expanding partnerships with the NHI, resulting in the need for the current Competition Commission enquiry into the drivers of prices in the private health sector. ${ }^{[16]}$

PPPs will require a close, transparent relationship between government and private providers. ${ }^{[16]}$ The SA health system will need to develop skilled management, and the capacity to choose PPPs that are strategically important to national goals. ${ }^{[16]}$

\section{Conclusion}

Equitable access and universal coverage through an NHI was envisioned in SA as early as the $1920 \mathrm{~s} .{ }^{[14]}$ With the prospect finally on the horizon, leaders need to make efforts, at every level of the health system, to ensure a smooth transition for the people who will become a part of it. The public should understand the value and reap the benefits of an extra payroll tax. Good governance is required, with a plan to eliminate corruption, and vision must be sought from stakeholders throughout society. Human resources could be more highly valued and efforts made to create acceptable working environments, to retain staff. Inequities of the past have to be accounted for by rigorous efforts to target those least capable of delivering, yet most in need of service. Data collection should be facilitated in a feasible and sustainable manner that adds value to future policy. Using PPPs with caution, technologies can be optimised by building relationships between competent management personnel.

Through considerations such as these, we recognise that the health system is, above all, a human system. Upon implementation of the NHI, and reform of the SA health system, government must therefore become attentive to all concerns, needs and aspirations of the people it serves.

Acknowledgements. Dr Dina Balabanova, London School of Hygiene and Tropical Medicine, for guidance and teaching in Health Systems.

Author contributions. Sole author.

Funding. None.

Conflict of interest. None.

1. Department of Health, South Africa. National Health Insurance for South Africa: Towards Universal Health Coverage. https://www.health-e.org.za/wp-content/uploads/2015/12/National-Health-Insurancefor-South-Africa-White-Paper.pdf (accessed 10 July 2017).

2. World Health Organization. What is universal health coverage? Geneva: WHO, 2014. http://www.who. int/features/qa/universal_health_coverage/en/ (accessed 10 February 2016).

World Health Organization Western Pacific Region. The WHO Health Systems Framework. Geneva: WHO, 2017. https://www.wpro.who.int/health_services/health_systems_framework/en/(accessed 10 July 2017). 
4. McIntyre D, Doherty J, Gilson L. A tale of two visions: The changing fortunes of Social Health Insurance in South Africa. Health Policy Plan 2003;18(1):47-58. https://doi.org/10.1093/heapol/18.1.47

5. Kraushaar D. The Kenya National Hospital Insurance Fund: What can we learn from thirty years' experience. Boston: Management Sciences for Health, 1997.

6. Okorafor OA. National health insurance reform in South Africa: Estimating the implications for 6. Okorafor OA. National health insurance reform in outh Africa: Estimating the implications for
demand for private health insurance. Appl Health Econ Health 2012;10(3):189-200. https://doi. demand for private health insurance. Ap
org/10.2165/11594830-000000000-00000

Tangcharoensathien V, Supachutikul A, Lertiendumrong J. The social security scheme in Thailand: What lessons can be drawn? Soc Sci Med 1999;48(7):913-923.

8. Ensor T. Developing health insurance in transitional Asia. Soc Sci Med 1999;48(7):871-879.

9. Baleta A. South Africa rolls out pilot health insurance scheme. Lancet 2012;379(9822):1185. https:// doi.org/10.1016/S0140-6736(12)60495-4

10. National Planning Commission, South Africa. Diagnostic Overview. http://www.education.gov. za/Portals/0/Documents/Publications/National\%20Planning $\% 20$ Commission\%20Diagnostics\%20 Overview\%20of\%20the\%20country.pdf?ver=2015-03-19-134928-000 (accessed 10 July 2017).

11. Marais DL, Petersen I. Health system governance to support integrated mental health care in South Africa: Challenges and opportunities. Int J Ment Health Syst 2015;9(1):1-21. https://doi. org/10.1186\%2Fs13033-015-0004-z
12. Onoka CA, Hanson K, Hanefeld J. Towards universal coverage: A policy analysis of the development of the National Health Insurance Scheme in Nigeria. Health Policy Plan 2015;30(9):1105-1117. https:// of the National Health Insurance
doi.org $/ 10.1093 /$ heapol/czul16

13. Bishai D, Ghaffar A, Kelley E, Kieny MP. Honouring the value of people in public health: A differen . Bishai D, Ghaffar A, Kelley E, Kieny MP. Honouring the value of people in public health: A different
kind of p-value. Bull World Health Organ 2015;93(9):661-662. https://doi.org/10.2471/BLT.14.149369 kind of p-value. Bull World Health Organ 2015;93(9):661-662. https://doi.org $10.2471 / B L T .14 .149369$
van Rensburg HC. South Africa's protracted struggle for equal distribution and equitable access - still 4. van Rensburg HC. South Africa's protracted struggle for equal distribution and equita
not there. Hum Resour Health 2014;12:26. https://doi.org/10.1186/1478-4491-12-26

15. Mayosi BM, Lawn JE, Niekerk A, Bradshaw D, Karim SSA, Coovadia HM. Health in South Africe: Changes and challenges since 2009. Lancet 2012;380(9858):2029-2043. https://doi.org/10.1016/S01406736(12)61814-5

6. Kula N, Fryatt RJ. Public-private interactions on health in South Africa: Opportunities for scaling up. Health Policy Plan 2014;29(5):560-569. https://doi.org/10.1093/heapol/czt042

17. Webster PC. Lesotho's controversial public-private partnership project. Lancet 2015;386(10007):19291931. https://doi.org/10.1016/S0140-6736(15)00959-9

Accepted 11 July 2017. 